\title{
Relationship to Corrosion Resistance-Thermal \\ Fatigue Boiler Tubes with the Heat \\ of the Defect Structure
}

\author{
Anna V. Pomazova*a, Tatyana V. Panova ${ }^{\text {b, }}$ \\ Aleksandr S. Zavorin ${ }^{\mathrm{c}}$ and Aleksandr I. Artamontsev ${ }^{\mathrm{c}}$ \\ ${ }^{a}$ Russian Laboratory Ltd. Research Examination Center \\ 7/8 Gubkin, Omsk, 644035, Russia \\ ${ }^{\mathrm{b}}$ Omsk F. M. Dostoevsky State University \\ 55a Mira, Omsk, 644077, Russia \\ ${ }^{c}$ National Research Tomsk Polytechnic University \\ 36 Lenin, Tomsk, 634050, Russia
}

The article presents the results of a study on the impact of multiple normalization of the thermal conductivity of carbon steel 20 used in the power system for the manufacture of pipes of heating surfaces. The effect of heat treatment on the emerging nature of corrosive deposits. It has been found that in addition to the phase state of steel 20 on the thermal conductivity value is influenced by structural changes in the steel during heat treatment. With increasing interlamellar distance and cementite platelets thickness thermal conductivity increases. Studies have shown that the thermal conductivity of sample tubes in the delivery state at a temperature close to the operating temperature $\left(300{ }^{\circ} \mathrm{C}\right)$, has a considerable scatter in the data (10 to 20\%). Analysis of the samples destroyed showed corrosion rate of thermal fatigue 1.4 times vary depending on the level and type of the thermophysical properties of the scale.

Keywords: thermal conductivity, normalization, structural-phase state, 20 steel, corrosion-thermal fatigue.

Citation: Pomazova A.V., Panova T.V., Zavorin A.S., Artamontsev A.I. Relationship to corrosion resistance-thermal fatigue boiler tubes with the heat of the defect structure, J. Sib. Fed. Univ. Eng. technol., 2017, 10(4), 557-571. DOI: 10.17516/1999494X-2017-10-4-557-571.

(C) Siberian Federal University. All rights reserved

* Corresponding author E-mail address: pomazova@yandex.ru 


\title{
Взаимосвязь стойкости
}

\section{к коррозионно-термической усталости котельных труб \\ с теплопроводностью дефектных структур}

\author{
А.В. Помазова ${ }^{a}$, Т.В. Панова ${ }^{6}$, \\ А.С. Заворин ${ }^{\text {в }}$, А.И. Артамонцев ${ }^{\text {в }}$ \\ аЗАО НДЦ НПФ «Русская лаборатория» \\ Россия, 644035, Омск, Губкина, 7/8 \\ ${ }^{6} О$ мский государственный университет \\ им. Ф.М. Достоевского \\ Россия, 644077, Омск, Мира, 55a \\ ${ }^{8}$ Национальный исследовательский \\ Томский политехнический университет \\ Россия, 634050, Томск, Ленина, 36
}

В статье представлены результаты исследования влияния многократной нормализации на коэффиџиент теплопроводности углеродистой стали 20, применяемой в теплоэнергетике для изготовления труб поверхностей нагрева. Установлено влияние термообработки на характер формирующихся коррозионных отложений. Обнаружено, что помимо фазового состояния стали 20 на величину теплопроводности оказывают влияние и структурные изменения, происходящие в стали при термообработке. По мере увеличения межпластинчатого расстояния и толщины пластинок иементита теплопроводность увеличивается. Проведенные исследования выявили, что коэффициент теплопроводности образцов труб в состоянии поставки при температуре, близкой к температуре эксплуатации $\left(300^{\circ} \mathrm{C}\right)$, имеет значительный разброс данных (от 10 до 20 \%). Анализ разрушенных образиов показал, что скорость развития коррозионно-термической усталости различается в 1,4 раза и зависит от уровня теплофизических свойств и вида окалины.

Ключевые слова: коэффищиент теплопроводности, нормализачия, структурно-фазовое состояние, сталь 20, коррозия.

\section{Введение}

Состояние поверхностей нагрева котлоагрегатов существенно влияет на ресурс и надежность работы тепломеханического оборудования электрических станций. Работа элементов котельного оборудования в значительной мере зависит от структуры и свойств применяемых материалов, а также обеспечивается соблюдением режимов эксплуатации.

Одной из причин эксплуатационного разрушения труб поверхностей нагрева является коррозионно-термическая усталость. Статистический анализ, проведенный в лаборатории разрушающего контроля в г. Омске, свидетельствует о том, что на долю этого механизма повреждения приходится $~ 15$ \% от общего количества повреждений теплообменных труб.

Коррозионно-термическая усталость металла (КТУ) - процесс постепенного накопления повреждений материала под действием многократных повторных температурных напряжений и коррозионной среды. В периоды пуска, останова, выхода на рабочие параметры происходит изменение режимов, что создает неоднородность температурного поля. Практически такие условия возникают всегда, когда движение по трубе пароводяной смеси носит переменный или 
пульсирующий характер, при этом часто и резко изменяется скорость движения эмульсии, ее паросодержание [1]. Кроме того, в процессе эксплуатации возможны такие ситуации, когда на горячую поверхность попадает среда с более низкой температурой, что способствует ускорению процесса коррозионно-термической усталости [2]. Очагами развития КТУ, как правило, служат язвы, каверны и другие поверхностные дефекты.

Влияние коррозионной среды на сопротивление усталостному разрушению исследовалось различными авторами $[3,4]$. Роль структуры поверхности и строение поверхностной оксидной пленки были рассмотрены в работе [5]. При этом экспериментальные исследования влияния структуры на сопротивление знакопеременным нагрузкам практически отсутствуют [2]. В работе [6] было показано, что скорость коррозии зависит от степени однородности микроструктуры, и установлен наиболее эффективный режим термической обработки углеродистой стали 20 , применяемой в теплоэнергетике для изготовления труб поверхностей нагрева. Термическая обработка по-разному влияет на коррозионные свойства, на изменения свойств образующихся защитных окисных пленок на поверхности металла, а также на теплофизические характеристики углеродистой стали.

Одной из основных характеристик работы элементов котла является величина тепловой нагрузки поверхности нагрева, по которой можно судить, насколько эффективно используется поверхность нагрева, проводить сравнение для всего агрегата или отдельных его частей [7]. Через материал поверхности нагрева, а также через слои внешних и внутренних отложений теплота передается за счет их теплопроводности. При этом от толщины и теплопроводности отложений очень зависит температура металла поверхности нагрева [8, 9]. В процессе термоциклирования наличие температурных градиентов приводит к термическим напряжениям. Анализ теплопроводности для прогнозирования термомеханической усталости, теплового сопротивления, оценки срока службы трубных элементов, работающих в условиях тепловой усталости, был представлен в модельной оценке в работах [10-12]. Авторы работы [13] показали, что теплопроводность структурных составляющих в процессе термообработки ограничивает размеры фаз, что затрудняет получение желаемой микроструктуры. При этом тепловая неравномерность является следствием неравномерности тепловосприятия, конструктивной нетождественности и гидравлической разверки. Неравномерность тепловосприятия связана с неоднородными распределениями температуры, скорости продуктов сгорания, циркулирующего теплоносителя и теплопроводности металла стенки трубы [14]. Корреляция между микроструктурой и теплопроводностью, связанная с дефектами структуры [15], приводит к увеличению теплопроводности в бинарных сплавах при уменьшении числа дефектов кристаллической решетки и мелкодисперсных частиц в процессе термообработки [16-18].

Экранные трубы из стали 20, подвергнутые термообработке согласно техническим условиям «Трубы стальные бесшовные для паровых котлов и трубопроводов» [19], не исследовались на характер влияния микроструктуры на теплопроводность. В связи с этим в настоящей работе проведено исследование влияния теплофизических характеристик труб из углеродистой стали 20 на стойкость к КТУ. Представляется актуальным изучение влияния многократной нормализации на теплопроводность такой стали, на характер формирующихся коррозионных отложений, а также выявление взаимосвязи между теплопроводностью дефектных структур котельных труб и стойкостью к коррозионно-термической усталости.

$$
-559-
$$




\section{Материалы и методы}

Образцы первой партии стали 20 (состав, мас. \%: углерод $0,185 \pm 0,016$, кремний $0,28 \pm 0,03$, марганец $0,49 \pm 0,03$, хром $0,085 \pm 0,008$, никель $0,035 \pm 0,008$, медь $0,041 \pm 0,008$, сера $0,004 \pm 0,002$, фосфор $0,007 \pm 0,002$, остальное железо), вырезанные из листового проката, подвергались многократной нормализации в электропечи камерной СНОЛ-1,4.2,5.1,2/12,5-И1 при температурах $900,910,920,930,940,950{ }^{\circ} \mathrm{C}$. Количество циклов при каждой температуре варьировалось от одного до пяти. Во второй партии были взяты образцы, поврежденные в результате развития коррозионно-термической усталости: две трубы потолочного пароперегревателя из стали 20 одинакового типоразмера Ø 42×5 мм после 122 (образец № 1) и 175 (образец № 2) тыс. эксплуатации при температуре $368^{\circ} \mathrm{C}$ и давлении 15,2 МПа. Для исследования теплопроводности были взяты образцы с менее нагруженной тыльной стороны. Морфологический анализ структурных составляющих стали проводился на металлографическом анализаторе фрагментов микроструктуры твердых тел «Ресурс С7», включающем в себя инвертированный микроскоп Olympus GF41 с программным обеспечением SIAMS Photolab (относительная погрешность измерений от $\pm 0,25$ (при увеличении до *500 включительно) до $\pm 0,65 \%$ (при увеличении свыше *500)).

Существующие модели расчета теплопроводности в зависимости от состава и температуры не показывают высокой точности [15], поэтому исследование коэффициента теплопроводности в настоящей работе проведено экспериментально стационарным методом неограниченной пластины [9]. Структурно-фазовое состоянии исследовалось на рентгеновском дифрактометре ДРОН-3М ( $\lambda_{\mathrm{Cu}}=1,54 \AA$ ). Механические испытания и оценка коррозионных отложений проводились, соответственно, на разрывной машине P-5 и на микроскопе Neophot-2 (погрешность измерения составила $5 \%$ ).

\section{Результаты и их обсуждение}

В теплоэнергетике используются введённые с 2004 г. технические условия, согласно которым котельные трубы из углеродистой стали 20 поставляют в термообработанном состоянии, после однократного режима нормализации в температурном интервале $920 \div 950{ }^{\circ} \mathrm{C}$ [19]. Экспериментальные зависимости изменения теплопроводности образцов от температуры испытания, полученные после однократной нормализации в диапазоне температур $900 \div 950{ }^{\circ} \mathrm{C}$, приведены на рис. 1. Они построены по методу наименьших квадратов и обобщают (аппроксимируют) экспериментальные данные, представленные в табл. 2.

Видно, что температура нормализации оказывает значительное влияние на коэффициент теплопроводности, который закономерно уменьшается при росте температуры испытания для всех режимов термообработки. При этом интенсивность снижения коэффициента теплопроводности возрастает с увеличением температуры нормализации. Начиная с температуры $920{ }^{\circ} \mathrm{C}$ угол наклона прямых практически одинаков, однако его величина отличается для каждого режима испытания. Коэффициент теплопроводности образцов, прошедших рекомендованную по техническим условиям термообработку в температурном интервале $920 \div 950{ }^{\circ} \mathrm{C}$, при температуре, близкой к температуре эксплуатации $\sim 300{ }^{\circ} \mathrm{C}$, имеет значительный разброс данных ( $10 \%)$. Разброс значений при этой температуре во всем исследованном температурном диапазоне нормализации $\left(900 \div 950{ }^{\circ} \mathrm{C}\right)$ также составляет $\sim 10 \%$. 
На рис. 2 показано повреждение образцов № 1 и № 2, взятых с прямых участков плавниковых труб потолочного пароперегревателя. Повреждение обоих образцов произошло с огневой стороны и представляет собой мелкие свищи. Оксидная пленка на наружной поверхности образца № 1 рыхлая, имеет повреждения в виде отслоений мелкими фрагментами на половине периметра с обнажением, но без коррозии металла (рис. $3 a$ ). Оксидная пленка на наружной поверхности образца № 2 плотная и имеет повреждения в виде редких отслоений мелкими фрагментами без обнажения и коррозии металла (рис. 3б). Нарушение целостности оксидной пленки приводит к тому, что на оголенной поверхности резко возрастает тепловая нагрузка, что способствует увеличению локальной температуры на этой части поверхности.

После удаления коррозионных отложений обнаружено поперечное растрескивание на наружной и внутренней поверхности обоих образцов (рис. 4, 5). Протяженность трещин составляет до 60 мм (рис. 5).

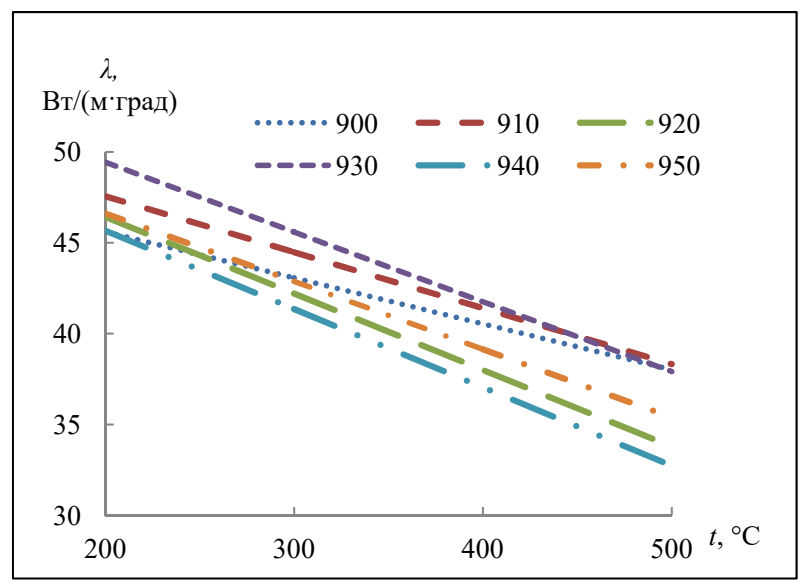

Рис. 1. Зависимость теплопроводности образцов от температуры после однократной нормализации, проведенной при различных температурах
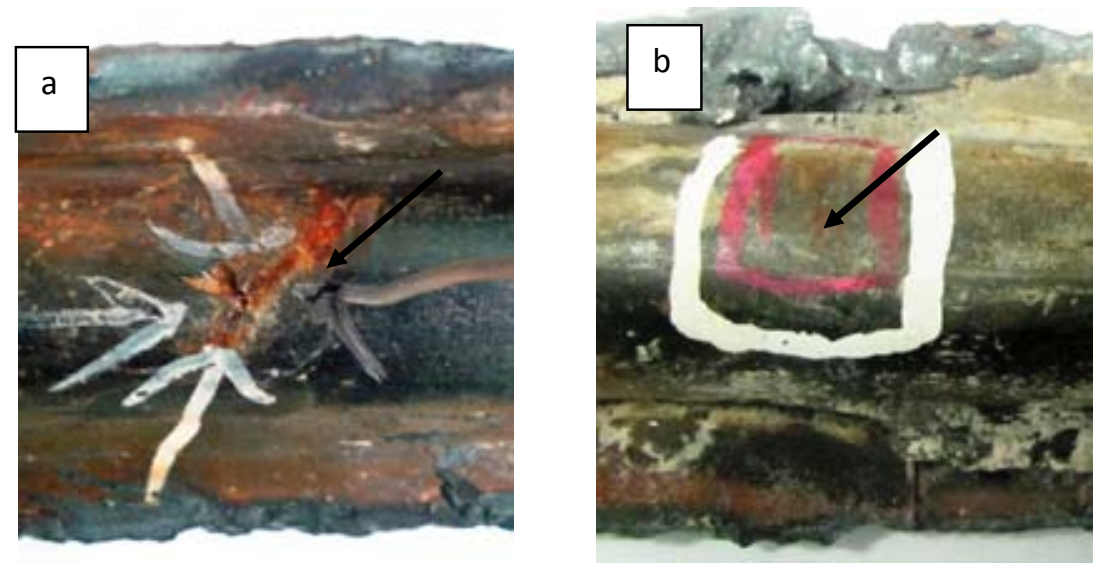

Рис. 2. Внешний вид повреждения образцов № 1 (a) и № 2 (b) 

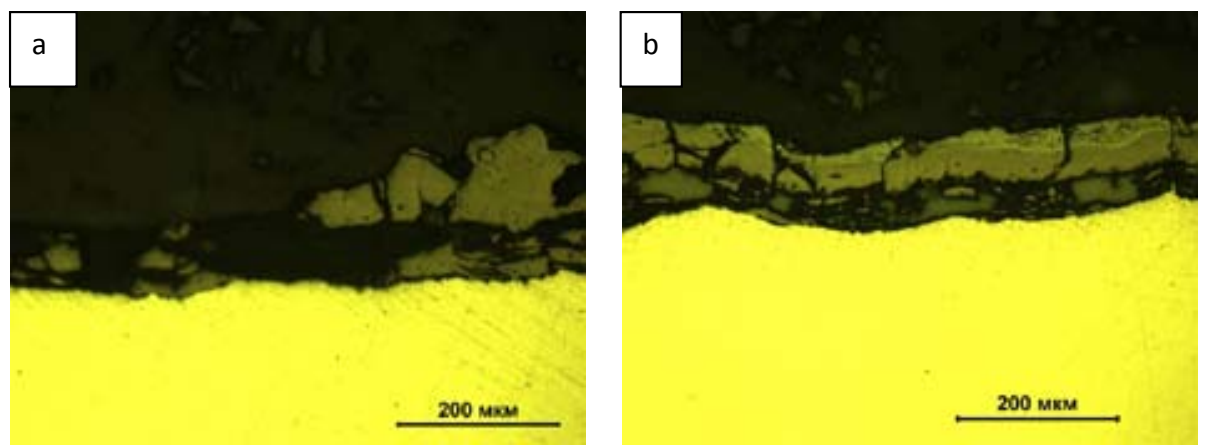

Рис. 3. Состояние окалины на наружной поверхности образцов № 1 (a) и № 2 (b) (нетравленый шлиф)
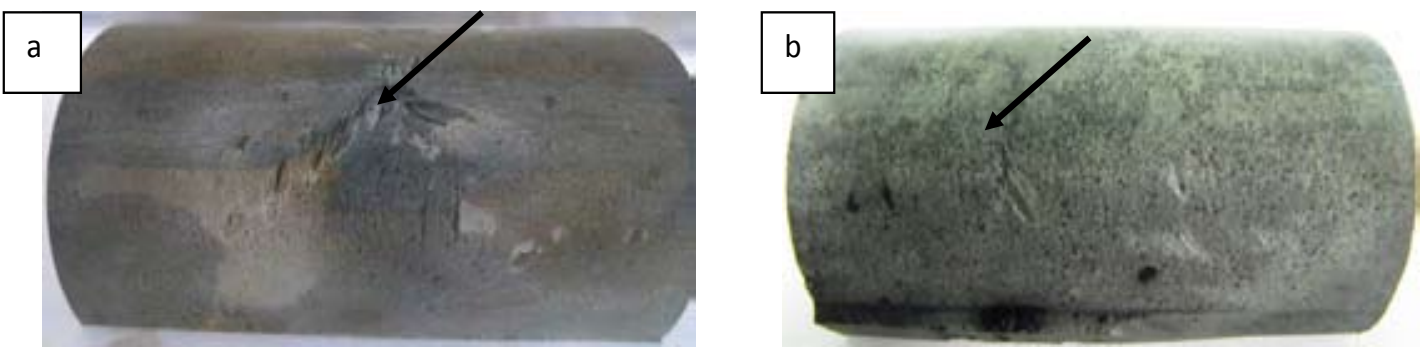

Рис. 4. Наружная поверхность поврежденных образцов № 1 (a) и № 2 (b) после удаления коррозионных отложений
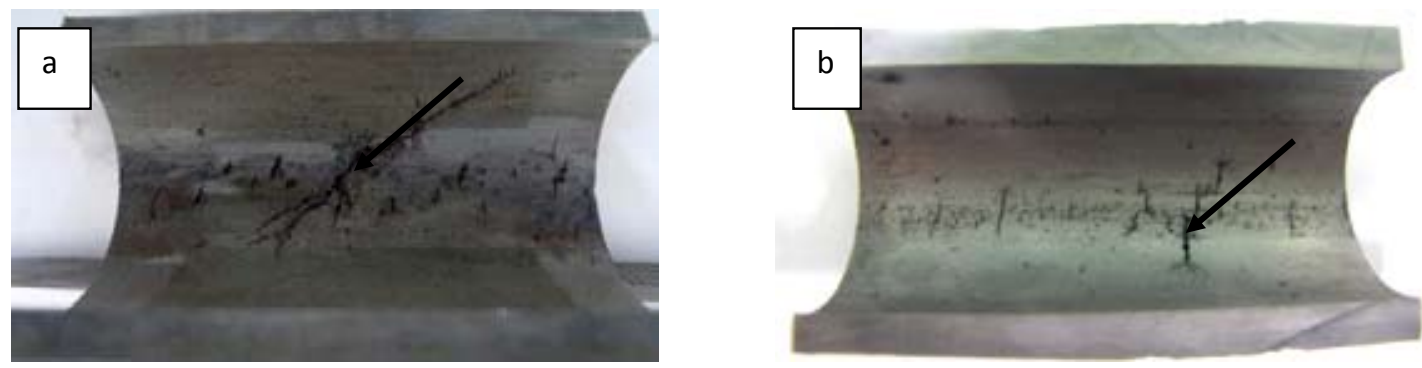

Рис. 5. Внутренняя поверхность поврежденных образцов № 1 (a) и № 2 (b) после удаления коррозионных отложений

Результаты механических испытаний, значения коэффициента теплопроводности, скорости развития КТУ, фактора разнозернистости основного металла приведены в табл. 1. Анализом механических характеристик установлено, что разница этих свойств между образцами незначительна и находится в пределах погрешности измерений. Однако при этом теплопроводность образцов отличается существенно.

Для установления причин трещинообразования вблизи мест повреждения были сделаны продольные срезы, которые показали траектории развития трещин КТУ (рис. 6). У образца № 1 траектория трещины более развита, из вершины трещина развивается по трем направлениям. 
Таблица 1. Предел прочности $\left(\sigma_{s}\right)$, предел текучести $\left(\sigma_{\mathrm{\tau}}\right)$, относительное удлинение $(\delta)$, относительное сужение $(\psi)$, коэффициент теплопроводности $(\lambda)$, фактор разнозернистости $\left(\mathrm{F}_{\mathrm{Z}}\right)$, скорость развития КТУ ( $\left.\mathrm{V}_{\text {кту }}\right)$ разрушенных образцов

\begin{tabular}{|c|c|c|c|c|c|c|c|}
\hline Образец & $\sigma_{s}, \mathrm{M \Pi а}$ & $\sigma_{m}, \mathrm{MПа}$ & $\delta, \%$ & $\psi, \%$ & $\begin{array}{c}\lambda, \mathrm{BT} / \\
(м \cdot г р а д)\end{array}$ & $\mathrm{F}_{\mathrm{Z}}$ & $\begin{array}{c}\mathrm{V}_{\text {Кту }} \\
\mathrm{MM} / 3 \mathrm{a} 10^{5} \text { ч }\end{array}$ \\
\hline $\begin{array}{l}\text { Основной металл } \\
\text { трубы № } 1\end{array}$ & $4,59 \pm 0,18$ & $3,44 \pm 0,14$ & $68,3 \pm 2,7$ & $36,4 \pm 1,5$ & 40,3 & 0,25 & 3,1 \\
\hline $\begin{array}{l}\text { Основной металл } \\
\text { трубы № } 2\end{array}$ & $4,72 \pm 0,19$ & $3,77 \pm 0,15$ & $65,3 \pm 2,6$ & $37,2 \pm 1,5$ & 48,2 & 0,26 & 2,2 \\
\hline $\begin{array}{l}\text { Требования } \\
\text { ТУ 14-3Р-55-2001 [19] }\end{array}$ & $4,20-5,60$ & $\geq 2,20$ & $\geq 45,0$ & $\geq 24,0$ & - & - & - \\
\hline
\end{tabular}
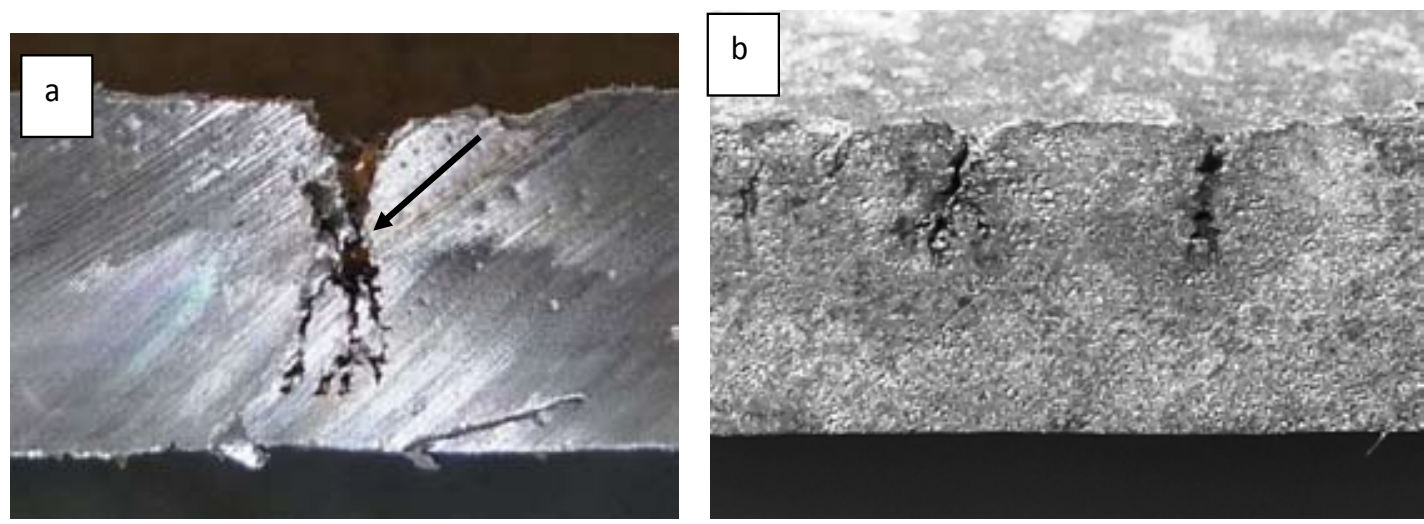

Рис. 6. Развитие трещины коррозионно-термической усталости по толщине стенки трубы образца № 1 (a) и № 2 (b)

Это отличие может быть связано как с разным структурным состоянием, так и с наличием градиента твердости то толщине стенки трубы, приводящего к сложнопрогнозируемому механизму развития трещины [10].

При металлографическом исследовании установлено, что трещины развиваются преимущественно от коррозионных язв и имеют транскристаллитный характер с пережимами в сечении, раздваивающимися по мере роста и заполненными продуктами коррозии (рис. 7). В первом образце траектория трещин более развита. Максимальная ширина межкристаллитных трещин в микроструктуре трубы № 1 составляет 190 мкм, в микроструктуре трубы № 2 - 115 мкм. Ширина межкристаллитных трещин двух образцов отличается в 1,6 раз. Микроструктура металла феррито-перлитная, со всех сторон трубы без значительных структурных изменений.

Анализ морфологии разрушенных зон показал, что, несмотря на разное время эксплуатации, разрушение осуществляется по одному и тому же механизму и определяющим фактором является коррозионно-термическая усталость, скорость которой различается в 1,4 раза и зависит от теплофизических свойств и вида окалины. Остальные контролируемые характеристики двух труб отличаются друг от друга незначительно. Значения коэффициентов теплопроводности отличаются на 20 \% и составляют 40,3 и 48,2 Вт/(м·град) для труб № 1 и № 2 соответственно. Это различие больше в два раза, чем было показано по аппроксимирующей зависимости

$$
-563-
$$



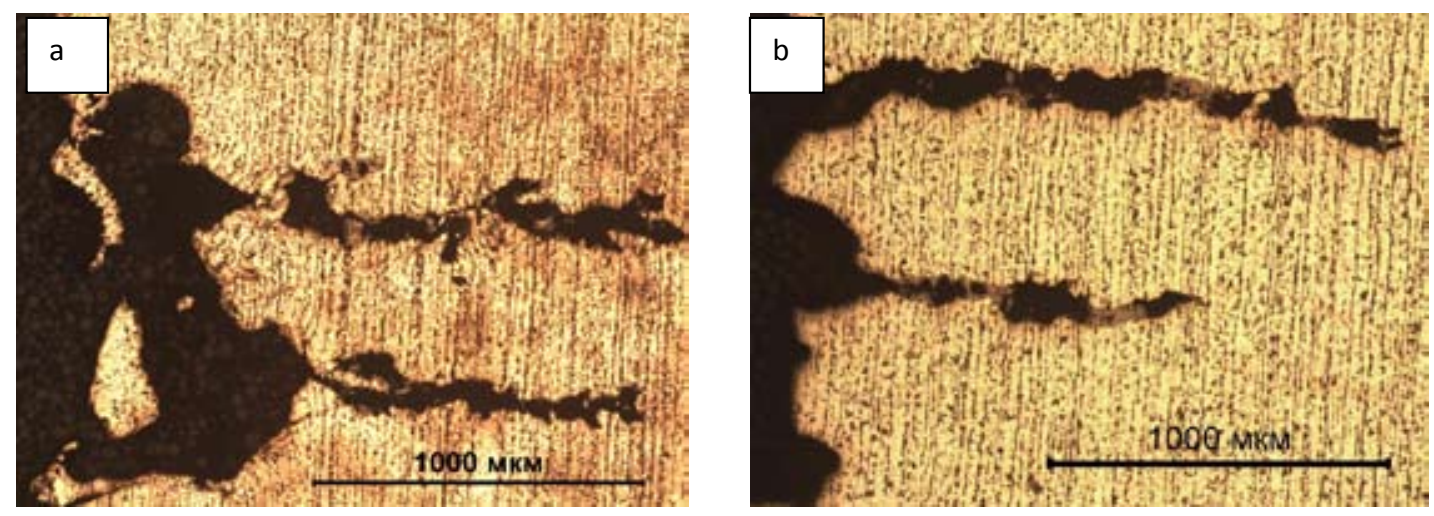

Рис. 7. Профиль поперечного сечения трещин коррозионно-термической усталости, развивающихся от коррозионных язв на внутренней поверхности образцов № 1 (a) и № 2 (b) (травленый шлиф)

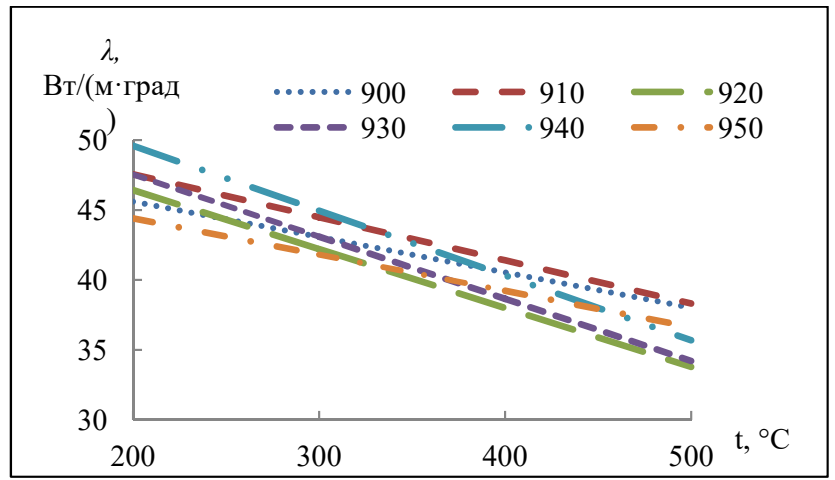

Рис. 8. Зависимость теплопроводности образцов от температуры после двукратной нормализации, проведенной при различных температурах

при проведении лабораторных испытаний (рис. 1). При одинаковых других свойствах труб оно, по-видимому, связано с более сложными процессами, дающими вклад в изменение теплопроводности при изготовлении труб из стали 20.

Поскольку ранее установлено, что режим двукратной нормализации приводит к значительному изменению микроструктурных, механических и коррозионных характеристик и улучшению однородности микроструктуры [20], были выполнены исследования теплопроводности образцов после двукратной нормализации, проведенной с интервалом $10{ }^{\circ} \mathrm{C}$ в температурном диапазоне $900 \div 950{ }^{\circ} \mathrm{C}$. Полученная зависимость теплопроводности образцов стали 20 от температуры после двукратной нормализации (рис. 8) показывает, что в образцах, подвергнутых двукратной нормализации, разброс значений коэффициента теплопроводности при температуре эксплуатации $\sim 300{ }^{\circ} \mathrm{C}$ уменьшается. При этом разброс значений коэффициента теплопроводности при температуре $300{ }^{\circ} \mathrm{C}$ во всем исследованном температурном диапазоне нормализации составляет $\sim 7 \%$, при $400{ }^{\circ} \mathrm{C}-\sim 12 \%$, при $200{ }^{\circ} \mathrm{C}-\sim 14 \%$, при $500{ }^{\circ} \mathrm{C}-\sim 24 \%$. Характер уменьшения коэффициента теплопроводности практически аналогичен варианту однократной нормализации. 


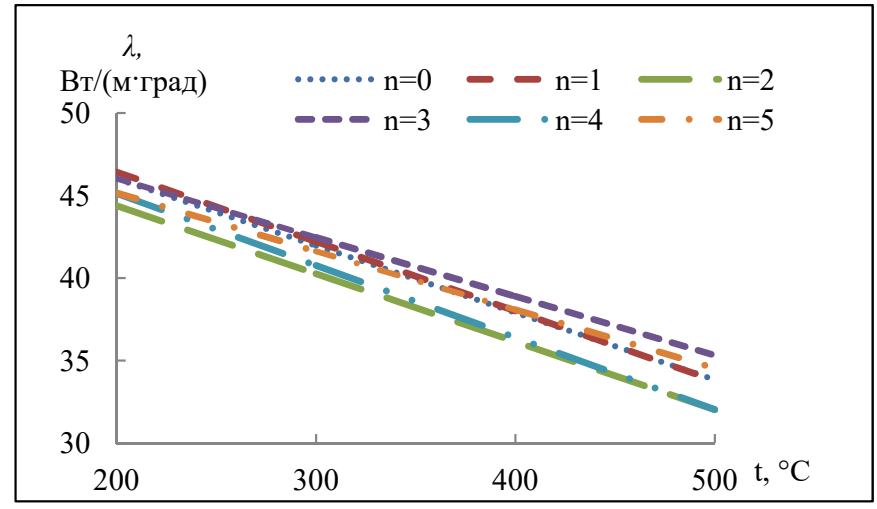

Рис. 9. Зависимость теплопроводности от температуры образцов после нормализации при $920{ }^{\circ} \mathrm{C}$ при различных количествах циклов $(\mathrm{n}=1 \div 5)$

Количество циклов нормализации при $920{ }^{\circ} \mathrm{C}$ влияет на значение коэффициента теплопроводности (рис. 9). Наибольшая величина коэффициента теплопроводности при температуре $300{ }^{\circ} \mathrm{C}$ наблюдается у образцов, прошедших пятикратный цикл нормализации, - 42,4 Вт/(м·град), минимальная - у образцов после четырехкратного цикла нормализации $-39,5$ Вт/(мгград).

Известно, что фазовые превращения, происходящие в стали при термообработке, оказывают существенное влияние на теплопроводность, которая изменяется в зависимости от объемной концентрации составляющих фаз [21]:

$$
\lambda_{c n n}=\lambda_{\phi}-\frac{N_{u}\left(\lambda_{\phi}-\lambda_{u}\right)^{N u}}{N_{u}\left(\frac{\lambda_{u}}{2 \lambda_{\phi}}\right)^{N \phi}}-\frac{N_{\phi} t}{30},
$$

где $\lambda_{\text {спл }}$ - коэффициент теплопроводности искомого сплава; $\lambda_{\phi}-$ коэффициент теплопроводности феррита при $0{ }^{\circ} \mathrm{C}\left(\lambda=76,8 \mathrm{Bт} /\left(\right.\right.$ м.град)); $\lambda_{\text {ц }}$ - коэффициент теплопроводности цементита $\left(\lambda=7,1 \mathrm{BT} /\left(\right.\right.$ м г град)); $\mathrm{N}_{ц}$ - доля цементита в сплаве; $\mathrm{N}_{\phi}-$ доля феррита в сплаве $\left(\mathrm{N}_{\phi}+\mathrm{N}_{\mathrm{u}}=1\right)$; $\mathrm{t}$ - температура сплава.

Формула применима для всех углеродистых сталей при температуре до $727^{\circ} \mathrm{C}$ и дает погрешность в этих условиях не более $10 \%$ [21]. Рентгенофазовый анализ показал, что в исходном состоянии и после всех видов термической обработки структура стали 20 является ферритоперлитной [20]. Относительная объемная доля ферритной фазы составляет 68,6 $\div 85,4$ \%, перлитной $-14,6 \div 31,4$ \% для исследуемого диапазона температур нормализации. Анализ полученных результатов расчета с использованием правила аддитивности и сравнение с экспериментальными данными по измерению теплопроводности показали отклонение от правила (табл. 2), с превышением допустимой погрешности после отдельных циклов нормализации. Очевидно, что при увеличении циклов нормализации стали 20 помимо фазового состояния на теплопроводность могут оказывать влияние и структурные изменения, такие как изменения межпластинчатого расстояния и толщины пластинок цементита, образование видманштетта и другие изменения степени однородности системы. Так, было установлено, что при образо- 
Anna V. Pomazova, Tatyana V. Panova... Relationship to Corrosion Resistance-Thermal Fatigue Boiler Tubes...

Таблица 2. Расчетные и экспериментальные определения коэффициента теплопроводности при $300{ }^{\circ} \mathrm{C}$

\begin{tabular}{|c|c|c|c|c|}
\hline \multirow{2}{*}{$\begin{array}{c}\text { Температура } \\
\text { нормализации }\end{array}$} & \multirow{2}{*}{$\mathrm{n}$} & \multicolumn{2}{|c|}{ Данные, Вт/(м · град) } & \multirow{2}{*}{ Погрешность, \% } \\
\hline & & Опытные & Расчетные & \\
\hline Исходное состояние & 0 & 41,7 & 39,1 & $-6,7$ \\
\hline \multirow{5}{*}{$900{ }^{\circ} \mathrm{C}$} & 1 & 42,6 & 49,9 & 14,6 \\
\hline & 2 & 41,1 & 55,3 & 25,8 \\
\hline & 3 & 42,4 & 36,7 & $-15,6$ \\
\hline & 4 & 41,5 & 40,9 & $-1,5$ \\
\hline & 5 & 40,7 & 57,4 & 29,0 \\
\hline \multirow{5}{*}{$910^{\circ} \mathrm{C}$} & 1 & 42,6 & 41,2 & $-3,5$ \\
\hline & 2 & 41,1 & 39,5 & $-3,9$ \\
\hline & 3 & 42,4 & 37,2 & $-14,0$ \\
\hline & 4 & 41,5 & 40,8 & $-1,7$ \\
\hline & 5 & 40,7 & 41,6 & 2,0 \\
\hline \multirow{5}{*}{$920^{\circ} \mathrm{C}$} & 1 & 40,4 & 39,5 & $-2,2$ \\
\hline & 2 & 41,4 & 39,5 & $-4,6$ \\
\hline & 3 & 42,0 & 38,0 & $-10,6$ \\
\hline & 4 & 39,5 & 39,5 & $-0,1$ \\
\hline & 5 & 42,4 & 36,6 & $-15,7$ \\
\hline \multirow{5}{*}{$930^{\circ} \mathrm{C}$} & 1 & 44,5 & 38,7 & $-14,9$ \\
\hline & 2 & 43,4 & 37,5 & $-15,8$ \\
\hline & 3 & 46,2 & 38,4 & $-20,3$ \\
\hline & 4 & 47,0 & 42,5 & $-10,5$ \\
\hline & 5 & 48,6 & 38,5 & $-26,1$ \\
\hline \multirow{5}{*}{$940{ }^{\circ} \mathrm{C}$} & 1 & 41,0 & 37,0 & $-10,8$ \\
\hline & 2 & 42,3 & 37,5 & $-13,0$ \\
\hline & 3 & 44,7 & 38,4 & $-16,5$ \\
\hline & 4 & 47,2 & 41,7 & $-13,3$ \\
\hline & 5 & 47,4 & 37,0 & $-27,9$ \\
\hline \multirow{5}{*}{$950{ }^{\circ} \mathrm{C}$} & 1 & 44,0 & 31,5 & $-39,6$ \\
\hline & 2 & 43,1 & 39,1 & $-10,3$ \\
\hline & 3 & 47,2 & 39,7 & $-18,9$ \\
\hline & 4 & 49,7 & 41,8 & $-19,0$ \\
\hline & 5 & 50,4 & 39,2 & $-28,6$ \\
\hline
\end{tabular}

вании видманштеттовой структуры после пяти циклов нормализации при $950{ }^{\circ} \mathrm{C}$ наблюдается максимальное значение теплопроводности. Полученные данные согласуются с результатами, приведенными в [13], где указано, что теплопроводность сплава может зависеть от размерных параметров микроструктуры, а также от состояния кристаллической решетки.

Зависимость коэффициента теплопроводности образцов стали 20 от размерных параметров перлита при $\mathrm{t}=300{ }^{\circ} \mathrm{C}$ (рис. 10) демонстрирует, что по мере увеличения межпластинчатого расстояния и толщины пластинок цементита теплопроводность увеличивается, что указывает 
на значительное влияние морфологии перлита на теплофизические свойства образцов из стали 20. Минимальное значение коэффициента теплопроводности соответствует межпластинчатому расстоянию $\sim 0,2$ мкм после четырех циклов нормализации при $920{ }^{\circ} \mathrm{C}$. При этом корреляционная связь между коэффициентом теплопроводности и степенью деформации кристаллической решетки отсутствует.

Сравнением изменения теплопроводности при $300{ }^{\circ} \mathrm{C}$ образцов стали 20 после всех циклов термообработки и при различных температурах нормализации (табл. 2 и рис. 11) установлено, что во всем исследуемом температурном интервале максимальное значение коэффициента теплопроводности наблюдается после пятикратного цикла нормализации при $950{ }^{\circ} \mathrm{C}$, минимальное - в режиме $920^{\circ} \mathrm{C}$ и двух циклах. При $\mathrm{n}=1$ и 2 независимо от температуры термообработки коэффициент теплопроводности практически не меняется. При анализе режимов, рекомендованных техническими условиями, видно, что они приводят к формированию разного уровня теплофизических свойств (разница $\sim 4$ Вт/(мгград)).

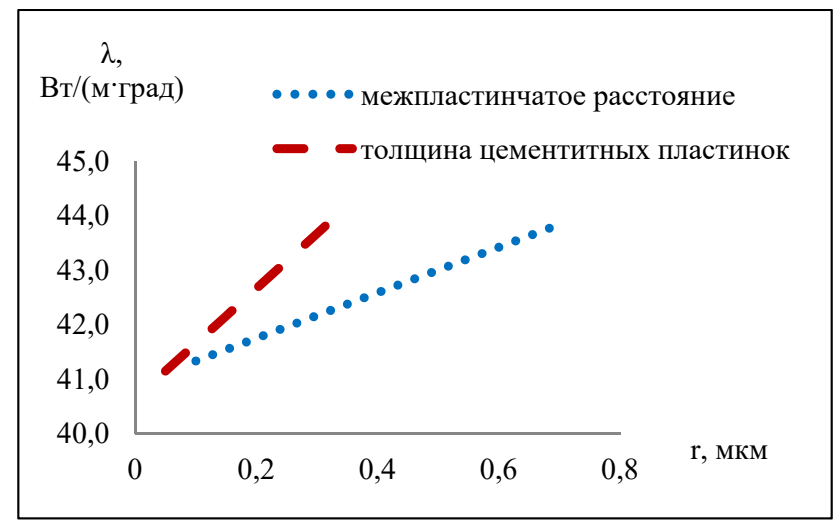

Рис. 10. Зависимость теплопроводности образцов стали 20 от размерных параметров перлита при $\mathrm{t}=300^{\circ} \mathrm{C}$

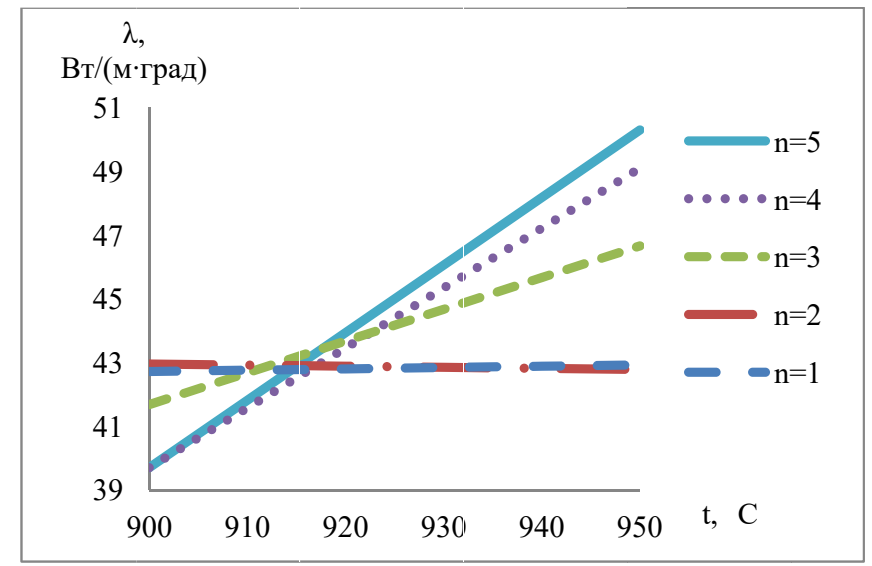

Рис. 11. Зависимость теплопроводности образцов при $300{ }^{\circ} \mathrm{C}$ после нормализации при различных температурах и количествах циклов

$$
-567-
$$




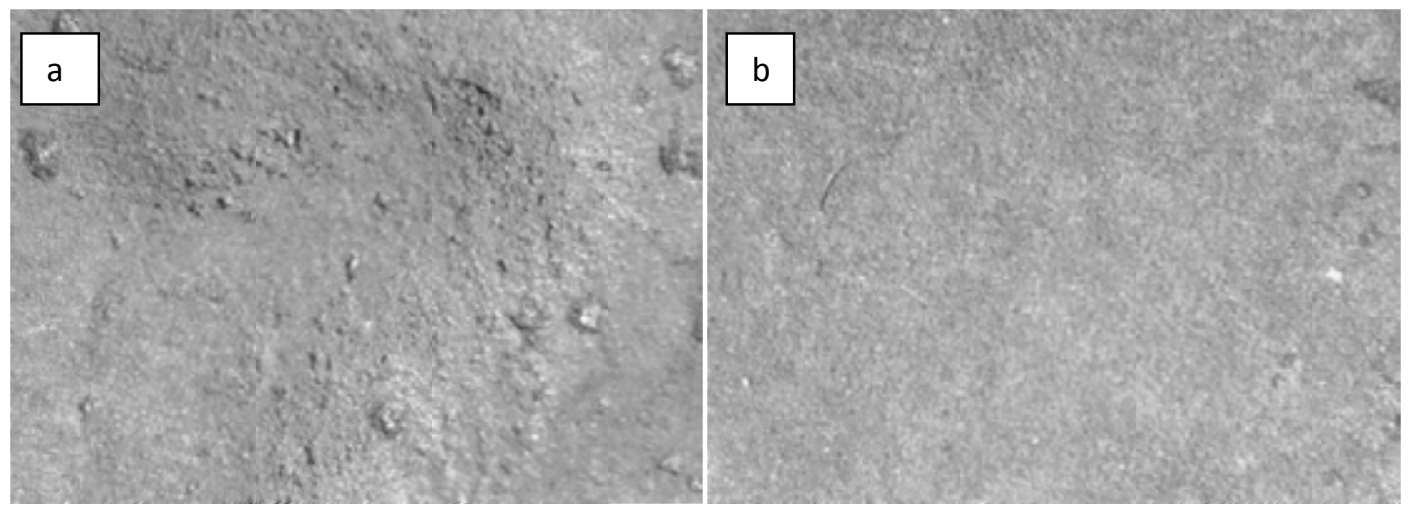

Рис. 12. Поверхность образца из стали 20 после пятикратной нормализации при $950{ }^{\circ} \mathrm{C}$ (a) и двукратной при $920^{\circ} \mathrm{C}(\mathrm{b})(\times 70)$

Режим, увеличивающий теплопроводность труб из стали 20 , благоприятен по условиям экономичности. Однако одновременно с этим после таких режимов термообработки на поверхности трубы формируется рыхлый неоднородный слой продуктов коррозии (рис. 12a), приводящий к снижению тепловой напряженности поверхности нагрева, что нивелирует эффект нормализации. На поверхности образцов стали 20, прошедших двукратную нормализацию при $920^{\circ} \mathrm{C}$, создается относительно ровный и плотный слой продуктов коррозии, имеющий достаточно хорошую адгезионную связь с поверхностью металла и защищающий ее от взаимодействия с рабочей средой (рис. 12б). Различие в значениях теплопроводности между этими образцами и образцами с максимальной теплопроводностью составляет $23 \%$. При этом разница в скоростях наружной коррозии - $62 \%$ [20].

Коэффициент теплопроводности отложений на два порядка ниже коэффициента теплопроводности стали. Поэтому даже очень тонкий слой коррозионных отложений представляет собой тепловую изоляцию. Существующие технологии уменьшения толщины коррозионных отложений направлены либо на их механическое удаление, либо на совершенствование процессов горения и качества топлива [22]. Вместе с тем полученные результаты показали, что уменьшение толщины отложений может быть достигнуто также за счет увеличения коррозионной стойкости материала трубы путем дополнительной термообработки [23] и за счет пассивации трубы в режиме паровоздушной обработки [24].

\section{Заключение}

Проведенные исследования показали, что коэффициент теплопроводности образцов труб в состоянии заводской поставки имеет при температуре, близкой к температуре эксплуатации $\left(300{ }^{\circ} \mathrm{C}\right)$, значительный разброс значений (от 10 до $20 \%$ ), что приводит к разной скорости развития КТУ в процессе эксплуатации. Обнаружено, что отдельные режимы термической обработки вызывают увеличение теплопроводности труб из стали 20. Однако одновременно с этим после таких режимов термообработки на поверхности трубы формируется рыхлый неоднородный слой продуктов коррозии, приводящий к снижению тепловой напряженности поверхности нагрева, что нивелирует эффект нормализации. Режим двукратной нормализации при $920{ }^{\circ} \mathrm{C}$, 
значительно улучшая антикоррозионные характеристики, много снижает теплопроводность, что, по-видимому, связано с формированием сорбитообразной структуры перлита.

\section{Список литературы}

[1] Акользин П.А. Коррозия металла паровых котлов. М.: Энергия, 1957. 224 с. [Akol'zin P.A. Corrosion of metal from steam boilers. Moskva, EHnergiya, 1957, 224 p. (in Russian)]

[2] Улиг Г.Г., Реви Р.У. Коррозия и борьба с ней. Введение в коррозионную науку и технику. Л.: Химия, 1989, 456 с. [Ulig G.G., Revi R.U. Corrosion and the fight against it. Introduction to corrosion science and technology. Leningrad, Himiya, 1989, 456 p. (in Russian)]

[3] Пачурин Г.В. Механизмы коррозионно-усталостного разрушения металлических материалов. Химия, биология, биотехнологии в современном мире: теория и практика: материаль международных научных конференции и симпозиума, 2013, 95-108 [Pachurin G.V. Mechanisms of Corrosion-Fatigue Failure of Metallic Materials, Chemistry, Biology, Biotechnology in the Modern World: Theory and Practice: Materials of the International Scientific Conference and Symposium, 2013, 95-108 (in Russian)]

[4] Похмурский В.И. Коррозионная усталость металлов. М.: Металлургия, 1985. 207 с. [Pohmurskij V.I. Corrosion fatigue of metals. Moskva, Metallurgiya, 1985, 207 p. (in Russian)]

[5] Пачурин Г.В. Роль структуры поверхности в коррозионной усталости деформированных металлических материалов. Современные проблемы науки и образования, 2014, 1, 209225 [Pachurin G.V. The Role of the Surface Structure in the Corrosion Fatigue of Deformed Metallic Materials. Modern Problems of Science and Education, 2014, 1, 209-225 (in Russian)]

[6] Помазова А.В., Панова Т.В., Геринг Г.И. Влияние разнозернистости структуры на коррозионную стойкость наружной поверхности труб из углеродистой стали 20 , применяемых в теплоэнергетике. Вестник Южно-Уральского государственного университета. Серия «Металлургия», 2014, 14(4), 37-44 [Pomazova A.V., Panova T.V., Gering G.I. Influence of Grain Heterogeneity on the Corrosion Resistance of the Outer Surface of Carbon Steel Pipes 20 Used in Heat Power Engineering. Bulletin of the South Ural State University. Series "Metallurgy", 2014, 14(4), 3744 (in Russian)]

[7] Резников М.И., Липов Ю.М. Паровые котль тепловых электростанциий. М.: Энергоиздат, 1981. 240 с. [Reznikov M.I., Lipov YU.M. Steam boilers of thermal power plants. Moskva, EHnergoizdat, 1981, 240 p. (in Russian)]

[8] Рудыка А.В., Шейкин С.И., Шлыгин В.В. Температурный режим труб топочных экранов котла П-67. Теплоэнергетика, 1991, 3, 32-36 [Rudyka A.V., Shejkin S.I., Shlygin V.V. The Temperature Conditions of the Pipes of Furnace Flues of the Boiler P-67, Thermal Engineering, 1991, 3, 32-36 (in Russian)]

[9] Заворин А.С., Кузьмин А.В., Раков Ю.Я. Методы определения теплопроводности конденсированных сред. Томск: Изд-во Томского политехнического университета, 2009. 184 с. [Zavorin A.S., Kuz'min A.V., Rakov YU.YA._Methods for determining the thermal conductivity of condensed media. Tomsk, Izd-vo Tomskogo politekhnicheskogo universiteta, 2009, 184 p. (in Russian)]

[10] Torabian N., Favier V., Ziaei-Rad S., Dirrenberger J., Adamski F., Ranc N. Thermal response of DP600 dual-phase steel under ultrasonic fatigue loading, Materials Science and Engineering: A, 2016, 677, 97-105.

$$
-569-
$$


[11] Li D., Barrett R.A., O’Donoghue P.E., Hyde C.J., O’Dowd N.P., Leen S.B. Micromechanical finite element modelling of thermo-mechanical fatigue for P91 steels, International Journal of Fatigue, 2016, 87, 192-202.

[12] Nilsson K., Dolci F., Seldis T., Ripplinger S., Grah A., Simonovski I. Assessment of thermal fatigue life for 316L and P91 pipe components at elevated temperatures, Engineering Fracture Mechanics, 2016, 168(A), 73-91.

[13] Peet M.J., Hasan H.S., Bhadeshia H.K.D.H. Prediction of thermal conductivity of steel, International Journal of Heat and Mass Transfer, 2011, 54 (11-12), 2602-2608.

[14] Богачев В.А. Повышение надежности поверхностей нагрева котлов ТЭС на основе исследования термогравитационных и магнитных явлений: дис. ... д-р. тех. наук: 01.04.14, 05.11.13. M., 2002, 295 c [Bogachev V.A. Increase of reliability of heating surfaces of thermal power plant boilers on the basis of investigation of thermogravitational and magnetic phenomena, Moscow, 2002, 295 p. (In Russia)]

[15] Misra D.K., Sumithra S., Chauhan N.S., Nolting W.M., Poudeu P.F.P., Stokes K. L. Correlation between microstructure and drastically reduced lattice thermal conductivity in bismuth telluride/ bismuth nanocomposites for high thermoelectric figure of merit, Materials Science in Semiconductor Processing, 2015, 40, 453-462.

[16] Zhong L., Peng J., Sun S., Wang Y., Lu Y., Pan F. Microstructure and Thermal Conductivity of As-Cast and As-Solutionized Mg-Rare Earth Binary Alloys, Journal of Materials Science \& Technology, 2016, 101, 160-165.

[17] Su C., Li D., Ying T., Zhou L., Li L., Zeng X. Effect of Nd content and heat treatment on the thermal conductivity of MgNd alloys, Journal of Alloys and Compounds, 2016, 685, 114-121.

[18] Kanaan A., Mazloum A., Sevostianov I. On the connections between plasticity parameters and electrical conductivities for austenitic, ferritic, and semi-austenitic stainless steel, International Journal of Engineering Science, 2016, 105, 28-37.

[19] ТУ 14-3Р-55-2001. Трубы стальные бесшовные для паровых котлов и трубопроводов. М.: РНИИТП, 2001. 84 с. [TU 14-3R-55-2001. Seamless Steel Tubes for Boilers and Pipelines. Moscow, RNIITP, 2001, 84 p. (in Russian)]

[20] Помазова А.В., Панова Т.В., Геринг Г.И. Роль структурных факторов в повышении коррозионной стойкости трубной стали при циклической термообработке. Известия Томского политехнического университета. 2015, 326(5), 15-21 [Pomazova A.V., Panova T.V., Gering G.I. The Role of Structural Factors in Increasing the Corrosion Resistance of Tubular Steel Under Cyclic Heat Treatment, Bulletin of the Tomsk Polytechnic University, 2015, 326(5), 15-21 (in Russian)]

[21] Давыдов С.В., Гуляев Ю.В., Симочкин В.В. Влияние теплофизических свойств углеродистых сталей на эвтектоидное превращение аустенита. Вестник Брянского государственного технического университета. 2008, 1, 4-9 [Davydov S.V., Gulyaev Yu.V., Simochkin V.V. Influence of Thermophysical Properties of Carbon Steels on the Eutectoid Transformation of Austenite, Bulletin of Bryansk State Technical University, 2008, 1, 4-9 (in Russian)]

[22] Отс А.А. Коррозия и износ поверхностей нагрева котлов. М.: Энергоатомиздат, 1987. 272 c. [Ots A.A. Corrosion and wear of heating surfaces of boilers. Moskva, EHnergoatomizdat, 1987, 272 p. (in Russian)] 
[23] Помазова А.В., Панова Т.В., Геринг Г.И. Способ повышения коррозионной стойскости труб из малоуглеродистых сталей. Патент РФ № 2580256. Бюллетень № 10, 2016 [Pomazova A.V., Panova T.V., Gering G.I. Method for increasing the corrosion resistance of pipes made of low-carbon steels. Patent of the Russian Federation № 2580256. Bulletin 10, 2016 (in Russian)].

[24] Любимова Л.Л., Заворин А.С., Лебедев Б.В. и др. Способ определения оптимальной температуры пассивации трубных элементов теплоэнергетического оборудования и устройство для коррозионных испытаний. Патент РФ № 2544313. Бюллетень № 8, 2015 [Lyubimova L.L., Zavorin A.S., Lebedev B.V. et al. Method for determining the optimum temperature of passivation of tube elements of heat power equipment and a device for corrosion testing. Patent of the Russian Federation 0 2544313. Bulletin 8, 2015 (in Russian)]. 